\title{
SEXUAL DISORDERS AFTER HEART TRANSPLANT
}

10.36740/WLek202010133

\author{
Kamila Fuczyło ${ }^{1}$, Magdalena Piegza ${ }^{2}$, Robert Pudlo ${ }^{2}$ \\ 'STUDENTS SCIENTIFIC ASSOCIATION, DEPARTMENT OF PSYCHIATRY, FACULTY OF MEDICAL SCIENCES IN ZABRZE, MEDICAL UNIVERSITY OF SILESIA, \\ TARNOWSKIE GORY, POLAND \\ ${ }^{2}$ DEPARTMENT OF PSYCHIATRY, FACULTY OF MEDICAL SCIENCES IN ZABRZE, MEDICAL UNIVERSITY OF SILESIA, TARNOWSKIE GORY, POLAND
}

\begin{abstract}
The aim: To systematize and bring the reader closer to knowledge about the occurrence of sexual disorders in people after heart transplantation based on available bibliography. Material and methods: A review of the literature on this topic from the last 30 years made with using the PubMed database, using a total of 17 articles.

Conclusions: The incidence of sexual dysfunction (SD) is higher in heart recipients than in the general population and erectile dysfunction is the most common. When the symptoms of dysfunction occur before the transplant - they do not improve, rather they get worse, which reduces the improvement in the quality of life of these patients compared to patients without sexual dysfunction. Improvement in quality of life is observed in patients with SD after heart transplantation, but not as pronounced as in subjects without sexual dysfunction. Some patients notice an increase in libido, with the genital response being insufficient or completely disappearing, which results in a decrease in the quality of relationships between partners and a deterioration in the quality of life. The cause of SD in heart recipients is unclear, but it is associated with the type of immunosuppression used, the level of sexual activity and the state of health of patients prior to transplantation. Nowadays patients after ortotrophic heart transplant live longer and their quality of life improves, but not in sexual terms. The articles concerned almost exclusively men, that is why the topic requires exploration in subsequent research.
\end{abstract}

KEY WORDS: heart transplantation, erectile dysfunction, sexual disorders

Wiad Lek. 2020;73(10):2277-2281

\section{INTRODUCTION}

Nowadays, more orthotopic heart transplantations $(\mathrm{OHT})$ are performed. According to the data from the International Society For Heart And Lung Transplantation from October 2019, in 2017 over 5.5 thousand heart transplant were made in the world. The median survival at the turn of $1992-2017$ is 11.9 years. There is also an upward trend in Poland, as the number of procedures performed at the turn of 2013-2018 increased from 76 to 147 transplants per year [1]. In the Zabrze center itself, 1,345 transplants were performed by the end of 2019 (from the register of the Silesian Center for Heart Diseases in Zabrze, Poland).

OHT is performed in patients with severe heart failure giving a chance for many years of survival. Studies on the quality of life of recipients show that despite general improvement $[2,3]$, satisfaction with sexual life has decreased $[2,4,5]$. This is caused by the deepening $[2,4$, $6]$ or persistence $[2,5]$ of sexual dysfunction in patients with a heart transplant. The incidence of sexual disorders (SD) reaches $74 \%$ after transplantation [2]. This shows the scale of the phenomenon, often overlooked or cursory in research, and suggests the need for in-depth research in this area. The purpose of this study is to organize knowledge and draw the reader's attention to the problems of sexual dysfunction in patients with heart transplants. In this work, the available literature from the last 30 years was reviewed, finally obtaining 17 articles that were analyzed.

\section{THE AIM}

This study serves to systematize and summarize knowledge about the occurrence of sexual disorders in patients with heart transplant described in the available literature.

\section{MATERIALS AND MEDHODS}

In order to create the study, the works found in the PubMed browser were reviewed. The following key phrases were used: "heart transplantation", "sexuality", "sexual disorders" and "sexual dysfunction". The keywords allowed to distinguish 34 articles in english language from the PubMed database. Some of the papers were rejected because they did not refer directly to the topic of sexual disorders of heart recipients or did not fall within the range of years considered in the study. Relevant items from the literature of selected articles have also been found and included in our work. Finally, 13 items from 2000-2020 and 4 studies from previous years (the oldest from 1990) were identified, which, according to the authors, was necessary in systematizing knowledge on the subject of this study.

\section{REVIEW AND DISCUSSION}

\section{INCIDENCE OF SEXUAL DYSFUNCTION AFTER HEART TRANSPLANTATION}

Sexual disorders are more common in recipients of solid organs than in the general population [7]. Among patients 
Table 1. The incidence of sexual dysfunction in heart transplant patient groups.

\begin{tabular}{|c|c|c|c|}
\hline Research & Measurement method & Participants & $\begin{array}{l}\text { Percentage of sexual } \\
\text { dysfunction after heart } \\
\text { transplantation }\end{array}$ \\
\hline Hasin et al. (2014) & Survey and interview & $\begin{array}{l}15 \text { men and } 2 \text { women, } \\
\text { average age: } 54 \text { years }\end{array}$ & 29 \\
\hline Caretta et al. (2013) & IIEF & $\begin{array}{c}77 \text { men, average age: } \\
61.6 \text { years }\end{array}$ & $\begin{array}{c}65 \\
\text { (24 before transplant) }\end{array}$ \\
\hline Serra et al. (2012) & IIEF & 52 men, average age: 54.2 years & 71 \\
\hline Phan et al. (2010) & IIEF & $\begin{array}{l}33 \text { men and } 6 \text { woman, } \\
\text { average age: } 61,4 \text { years }\end{array}$ & $\begin{array}{c}61 \\
(78-\text { men, } 50-\text { women) }\end{array}$ \\
\hline Basile et al. (2001) & SESAMO & 23 men, average age: 56 years & 74 \\
\hline Aravot et al. (2000) & Interview & $\begin{array}{l}9 \text { men and } 1 \text { woman, average age: } \\
54 \text { years }\end{array}$ & 20 \\
\hline Muligan et al. (1991) & Survey & 71 men, average age: 47.9 & $\begin{array}{c}60 \\
\text { (44 before transplant) }\end{array}$ \\
\hline
\end{tabular}

ILEF - International Index of Erectile Function;

SESAMO - Sexuality Evaluation Schedule Assessment Monitoring

with a heart transplant, these disorders are particularly common (Table 1). OHT is the ultimate and invasive, life-saving procedure for patients with severe organ failure. Patients qualified for transplantation are characterized by deteriorated physical condition, which is associated with reduced sexual activity.

Sexual disorder is noted in patients eligible for surgery $[2,4,6]$. The most common are: erectile dysfunction and orgasmic function [2,4] and ejaculation weakness [2]. It would be expected that sexual dysfunction would improve after surgery. However, studies show that pre-transplant abnormalities persist $[2,4,5]$. Moreover, their incidence increases from $24 \%$ of SD patients before surgery to up to $65 \%$ who report post-transplant dysfunctions [6]. In a study by Muligan et al. men after transplantation described their health as good and reported that they were physically active during the day [4]. The time from transplantation was from 3 to 80 months. Libido of subjects and their sexual partners prior to transplantation was defined as "strong". It persisted in recipients after surgery or increased statistically insignificantly, while it increased by about $20 \%$ in their sexual partners. In contrast to libido, the quality of penile erection and the ability to achieve orgasm have been permanently weakened and their gradual decline has been noted over time after transplantation. The subjective perception of your health positively correlated with the increase in libido and age negatively with the penile stiffness. Anorgasmia was reported by $44 \%$ before and $60 \%$ after surgery. The frequency of intercourse after transplantation was adequate to the level of sexual activity before surgery and the quality of erection achieved after transplantation. There was no significant relationship to exercise tolerance, immunosuppression used, and the type and amount of drugs. In another work mentioned earlier, entirely devoted to sexual disorders in heart recipients, 23 men were examined. Women were not included because three out of six subjects had high scores on the Hamilton Depression
Scale [2]. The results of the SESAMO (Sexuality Evaluation Schedule Assessment Monitoring) study showed that most patients indicated at least two pre-existing sexual disorders. Most often they were impaired ejaculation and erection quality. After transplantation, 3 patients did not engage in sexual activity, in the remaining patients the frequency of intercourse ranged from one to two a week. Half of the respondents considered this frequency to be unsatisfactory [2]. Both reports presented show that sexual dysfunctions occurring before transplantation after surgery persist or worsen, which reduces the quality of relationships between partners $[2,4]$. Even if patients were satisfied with their previous sex life and see improvements in transplant health, along with increased libido and desire, the overall sex life is not satisfying for them. Also in studies conducted among 79 people, being at least 6 months after heart transplantation, $61 \%$ of participants $(78 \%$ men and $50 \%$ women) confirmed the occurrence of SD. Patients with these disorders were in worse condition, especially physical. The subjects in better general health before surgery showed lower results of sexual dysfunction after surgery [5]. Patients with sexual dysfunction after transplantation did not differ significantly from subjects without SD in terms of mental health, including depressive symptoms [5]. Ischemic cardiomyopathy was a more frequent indication for transplantation in patients with erectile dysfunction (45\%) compared to the group without sexual dysfunction (20\%) [6].

In turn, in a small clinical study on the quality of life of patients with a heart transplant for over 5 years, 8 out of 10 respondents showed satisfaction with their sex life [8]. People reporting impotence were accompanied by additional diseases that could affect the occurrence of sexual dysfunction (glycogen storage disease, insulin-dependent diabetes). In patients who lived more than 5 years after heart transplantation, the authors of this study noticed a significant improvement in general functioning, relating to 
physical activity, job opportunities and the sexual quality of life component. It is noteworthy that only 10 people took part in the described project, which may affect the result of the lack of significant sexual disorders associated with transplantation. Also in a study comparing the frequency of sexual dysfunction in patients with a left ventricular assist device (LVD) and with a transplanted heart, the percentage of satisfied sex life was 29\% (LVD) and as much as $71 \%$ for patients with a transplanted heart in the first two years after surgery [9].

\section{SEXUAL ASPECT OF THE QUALITY OF LIFE OF PATIENTS WITH A TRANSPLANTED HEART}

Data collected by Burra and De Bona confirm the improvement in the quality of life of recipients with solid organ transplantation [3]. Especially a heart transplant has a significant impact on the quality of life of the recipient, because this organ is perceived as a center of feelings and emotions [3]. Psychological factors such as less stress, greater access to information, better perception of one's health and improved relationship have the greatest impact on the change in the quality of life of recipients in the first year after heart transplant [10]. Studies confirm the improvement of the quality of life also in later years on the physical, social and psychological level [3]. Sexual functions are considered to be an essential aspect of quality of life for patients after heart transplantation $[4,5]$. Patients with worse health before surgery showed less improvement in the quality of life after transplantation [5]. This also applies to sex life. Recipients with pre-transplant sexual dysfunction, contrary to the expected result, did not show improvement in this aspect $[2,5]$ or dysfunctions have even deepened $[2,4,6]$. Even if the patients were satisfied with their previous sexual experiences, and after the surgery they recovered correctly with the increase of libido and desire, the overall sex life was not satisfactory for them $[2$, 4]. In addition, in patients reporting post-transplant sexual dysfunction, the improvement in quality of life occurred, although it was not as significant as in patients without SD [5]. In psychological terms, these problems relate to fear of death during ejaculation, the impact of drugs on sex interest and the possibility of intercourse, appearance concerns, depressive symptoms, uncertainty about donor sexuality, and changed roles and responsibilities in the family [11].

\section{VASCULAR ASPECT OF SEXUAL DYSFUNCTION IN HEART TRANSPLANT PATIENTS}

The most common sexual disorder occurring in heart transplanted patients, as mentioned before, is erectile dysfunction $[5,6]$. A number of factors play a role in the erection mechanism of the penis, including neurological, vascular, endocrine and psychological factors. Pathology in any of these can lead to problems getting or maintaining a satisfying erection. A study by Caret et al. shows that erectile dysfunction is more common in patients whose heart transplant was caused by ischemic cardiomyopathy.
Transplant patients with sexual dysfunction showed lower peak systolic velocity, greater intima-media thickness of the penile vessel wall ( $26.7 \%$ to $5.2 \%)$, peripheral vascular disease $(60.87 \%$ to $26.1 \%)$ and vasculopathy coronary artery disease ( $45.8 \%$ to $25.8 \%$ ) compared to patients without DS (6). A reduction in coronary reserve in patients with SD was also noted. Erectile dysfunction has also been associated with factors affecting endothelial dysfunction and traditional risk factors for cardiovascular disease such as cholesterol levels, hypertriglyceridemia, diabetes, hypertension and abdominal obesity $[6,12]$.

\section{PHARMACOLOGICAL ASPECT OF SEXUAL DYSFUNCTION IN PATIENTS AFTER HEART TRANSPLANTATION}

Patients with a transplanted heart take immunosuppressants for the rest of their lives. They contribute to an increase in the incidence of sexual dysfunction in these patients, so appropriate drug selection and dose should always be considered. In Fleischer et al. low levels of free and total testosterone were most common in the early post-transplant period. It was also associated with low levels of luteinizing (LH) and follicle-stimulating (FSH) hormones, suggesting that the mechanism was suppression of the hypothalamic-pituitary-gonadal axes by taken prednisone [13]. Testosterone levels normalized in most patients within 6 months. Recipients with persistent lowered testosterone (up to 2 years) had elevated FSH and LH hormones, suggesting testicular dysfunction. In turn, patients treated with sirolimus were characterized by reduced levels of testosterone and elevated levels of LH and FSH [14, 15]. Therefore, recipients of the heart should have periodic testosterone levels to avoid hypogonadism. Research shows that these levels also depended on age, renal function and the time of immunosuppression used [14]. Sirolimus and calcineurin inhibitors have the effect of enabling erection [13]. However, based on the survey conducted in patients after heart transplantation, there was no significant difference in sexual performance between patients treated with sirolimus and the control group not taking the drug [15]. The correlation between testosterone levels and sexual dysfunction in this particular group of patients must still be studied. Other drugs, such as beta-blockers, digoxin and diuretics, also contribute to the increase in SD, in contrast to calcium channel blockers, which are somewhat more beneficial and allow the improvement of sexual function. In another report, more frequent sexual dysfunction was observed in 52 patients treated with everolimus [12]. The drug caused a decrease in total and free testosterone and an increase in LH and FSH. The results did not correlate with age, etiology of heart failure, smoking, hypertension and the use of antihypertensive and antidepressant drugs.

Hypogonadism is a major endocrine condition potentially affecting erectile dysfunction. In studies conducted by Serra et al. It occurred in $1 / 3$ of examined men with heart transplants with sexual disorders. He was not age-related, most often it affected men between 50 and 59 
years old. Positively correlated with the level of cholesterol and triglycerides, body mass index (BMI) and diabetic disorders [12]. An increased incidence of hypogonadism occurred in patients receiving triple immunosuppressive therapy (ciclosporin, everolimus and prednisone), and was particularly associated with everolimus. A positive correlation between ciclosporin level and free testosterone level was noted. In patients after heart transplantation, low testosterone levels were also associated with altered glucose levels, high systolic pressure, dyslipidemia and abdominal obesity [12]. It has been demonstrated that the use of angiotensin converting enzyme inhibitors in the treatment of hypertension correlates with the occurrence of erectile dysfunction [12]. In addition, immunosuppressive drugs may weaken the proliferation of progenitor cells that can differentiate into epithelial and smooth muscle cells, thereby affecting the vascular wall [16]. Ciclosporin may accelerate the aging process of cells and reduce nitric oxide levels, which in turn leads to endothelial dysfunction and erectile dysfunction [17].

\section{TREATMENT}

The vast majority of publications related to the treatment of sexual disorders in recipients of solid organs relate to patients with transplanted kidneys [7]. This treatment uses phosphodiesterase-5 inhibitors (Sildenafil), injections of prostaglandin E1 together with papaverine (Alprostadil at a dose of $10-40 \mathrm{mg}$ ) into the cavernous bodies and penile prostheses [7]. To date, successful treatment of SD in patients with heart transplanted prostaglandin E1 has been successfully used in $90 \%$ of patients without noticeable adverse side effects. Several patients have also reported a return of spontaneous erection after the described injections. However, it was a single study and it is difficult to draw general conclusions based on it. The fact remains that there are no studies on the treatment of SD recipients of the heart, which is a gap that is difficult to overlook in the literature on the subject.

\section{CONCLUSIONS}

A heart transplant not only enables the patient to extend life, but also improves his quality. However, this improvement is less in people who have sexual dysfunction. People who qualify for a heart transplant are characterized by a significant degree of advancement of heart disease and deterioration of their overall health, which may result in sexual problems. Contrary to hypothesis, the new heart does not improve previously existing erectile dysfunction and orgasm. These disorders deepen or persist with an increase in libido and desire, which is associated with a weakening of relationships between partners, growing frustration and ultimately reduces the improvement of quality of life after transplantation. The exact cause of sexual disorder in heart transplant patients has not been identified yet. Some authors point to vascular problems along with endothelial dysfunction. The impact of used immunosuppression, which reduces testosterone levels, which can lead to hypogonadism and, as a consequence, sexual disorders is also undeniable. Also the fear of death during sexual intercourse, uncertainty about the possibility of having sex, as well as the sexuality of the donor, as well as the change and division of roles in the family lead to avoid sexual contact with the partner. Sexual functioning after heart transplantation is unsatisfactory for patients and they are willing to improve it. The limitation of this work is its focus mainly on the male part of the population. So far, few studies have addressed the issue of sexual dysfunction in heart transplant patients. Given the frequency of this phenomenon and its health and social consequences, it seems reasonable to thoroughly explore the problem of sexual dysfunction in heart recipients. The most important are three directions of action: the choice of safer combinations of immunosuppressive drugs for sexual functions, the development of post-transplant sexual dysfunction treatment methods and psychotherapy methods to help recipients return to satisfactory sexual functioning. Perhaps it would also be expedient to implement targeted sexual rehabilitation for heart recipients.

\section{REFERENCES}

1. POLTRANSPLANT; Biuletyn informacyjny nr 2 (28) Lipiec 2018 ISSN $1428-0825 ; 22 / 13$

2. Basile A, Maccherini M, Diciolla F, et al. Sexual Disorders After Heart Transplantation. Transplant Proc. Feb-Mar 2001;33(1-2):1917-9.

3. Burra $\mathrm{P}, \mathrm{De}$ Bona M. Quality of life following organ transplantation. Transpl Int. 2007 May;20(5):397-409.

4. Mulligan T, Sheehan H, BSN, Hanrahan J. Sexual Function After Heart Transplantation. J Heart Lung Transplan. Jan-Feb 1991;10(1 Pt 1):125-8.

5. Phan A, IsHak WW, Shen BJ, Fuess J, Philip K, Bresee C, Czer L, Schwarz ER. Persistent Sexual Dysfunction Impairs Quality of Life after Cardiac Transplantation. J Sex Med. 2010 Aug;7(8):2765-73.

6. Caretta N, Feltrin G, Tarantini G, et al. Erectile Dysfunction, Penile Atherosclerosis and Coronary Artery Vasculopathy in Heart Transplant Recipients. J Sex Med. 2013 Sep;10(9):2295-302.

7. Payne K, Popat S, Lipshultz LI, Thirumavalavan N. The Prevelence and Treatment of Erectile Dysfunction in Male Solid Organ Transplant Recipients. Sex Med Rev.2019 Dec 16;\$2050-0521(19)30102-7. doi: 10.1016/j.sxmr.2019.10.002.

8. Aravot D, Berman M, Ben-Gal T, Sahar G, Vidne B. Functional Status and Quality of Life of Heart Transplant Recipients Surviving Beyond 5 Years. Transplant Proc. 2000 Jun; 32(4):731-2.

9. Hasin T, Jaarsma T, Murninkas D, et al. Sexual function in patients supported with left ventricular assist device and with heart transplant. ESC Heart Fail. 2014 Dec;1(2):103-109.

10. Grady KL, Jalowiec A, White-Williams C. Predictors of quality of life in patients at one year after heart transplantation. J Heart Lung Transplant 1999;18:202.

11. Tabler JB, Frierson RL. Sexual concerns after heart transplantation. J Heart Transplant 1990; 9:397-403.

12. Serra E, Porcu M, Minerba L, et al. High prevalence of male hypogonadism and sexual dysfunction in long-term clinically stable heart transplantation recipient. Int J Cardiol. 2012 Mar 22;155(3):476-7.

13. Fleischer J, McMahon D, Hembree W, Addesso V, Longcope Ch, Shan E. Serum Testosterone Levels After Cardiac Transplantation. Transplantation. 2008 Mar 27;85(6):834 
14. Kaczmarek I, Groetzner J, Adamidis I, et al. Sirolimus Impairs Gonadal Function in Heart Transplant Recipients. Am J Transplant. 2004 Jul;4(7):1084-8.

15. Huyghe E, Zairi A, Nohra J, Kamar N, Plante P, Rostaing L. Gonadal impact of target of rapamycin inhibitors (sirolimus and everolimus) in male patients: an overview. Transpl Int. 2007 Apr;20(4):305-11.

16. Davies WR, Wang S, Oi K, Bailey KR, Tazelaar H, Caplice NM, McGregor CGA. Cyclosporine Decreases Vascular Progenitor Cell Numbers After Cardiac Transplantation and Attenuates Progenitor Cell Growth in Vitro. J Heart Lung Transplant. 2005 Nov;24(11):1868-77.doi: 10.1016/j. healun.2005.04.004. Epub 2005 Aug 8

17. Ramzy D, Rao V, Tumiati LC, Xu N, Miriuka S, Delgado D, Ross HJ. Role of endothelin-1 and Nitric Oxide Bioavailability in TransplantRelated Vascular Injury: Comparative Effects of Rapamycin and Cyclosporine. Circulation. 2006 Jul 4;114 (1 Suppl):I214-9.doi: 10.1161/ CIRCULATIONAHA.105.000471.

\section{ORCID and contributionship}

Kamila Fuczyło - 0000-0002-3443-8663 B,D,F

Magdalena Piegza - 0000-0002-8009-7118 ${ }^{\text {A,B,D,E }}$

Robert Pudlo - 0000-0002-5748-0063 A,E,F

\section{Conflict of interest}

Authors declare no conflict of interest.

\section{CORRESPONDING AUTHOR}

Kamila Fuczyło

Students Scientific Association

Chair and Clinical Department of Psychiatry in Tarnowskie Góry,

Medical University of Silesia in Katowice, Poland;

e-mail:kamilafuczylo@gmail.com

Received: 27.08 .2020

Accepted: 02.10 .2020

A - Work concept and design, B - Data collection and analysis, C - Responsibility for statistical analysis,

D-Writing the article, $\mathbf{E}$-Critical review, $\mathbf{F}$ - Final approval of the article 